\title{
Sol-Gel Titanium Dioxide Nanoparticles: Preparation and Structural Characterization
}

\author{
Oon Lee Kang, ${ }^{1}$ Azizan Ahmad, ${ }^{1}$ Usman Ali Rana, ${ }^{2}$ and Nur Hasyareeda Hassan ${ }^{1}$ \\ ${ }^{1}$ Faculty of Science and Technology, Universiti Kebangsaan Malaysia, 43600 Bangi, Selangor, Malaysia \\ ${ }^{2}$ Sustainable Energy Technologies (SET) Center, King Saud University, P.O. Box 800, Riyadh 11421, Saudi Arabia
}

Correspondence should be addressed to Nur Hasyareeda Hassan; syareeda@ukm.edu.my

Received 29 June 2016; Accepted 15 November 2016

Academic Editor: Paresh Chandra Ray

Copyright (C) 2016 Oon Lee Kang et al. This is an open access article distributed under the Creative Commons Attribution License, which permits unrestricted use, distribution, and reproduction in any medium, provided the original work is properly cited.

Titanium dioxide $\left(\mathrm{TiO}_{2}\right)$ nanoparticle was achieved in an alternative sol-gel route, as involved in $1 \mathrm{M}$ acidic solution: $\mathrm{HCl}-$ tetrahydrofuran ( $\mathrm{HCl}-\mathrm{THF}), \mathrm{HNO}_{3}$-tetrahydrofuran $\left(\mathrm{HNO}_{3}\right.$-THF), and $\mathrm{ClHNO}_{2}$-tetrahydrofuran $\left(\mathrm{ClHNO}_{2}\right.$-THF) solution. Resultant $\mathrm{TiO}_{2}$ nanoparticle was further investigated in a systematic analytical approach. Nanoscale $\mathrm{TiO}_{2}$ structure was observed at a moderate hydrolysis ratio $\left(8 \leq R_{H} \leq 16\right)$. Particle size range was much narrower in an aprotic $\mathrm{HNO}_{3}$-THF medium, as compared to a differential HCl-THF medium. Biphasic $\mathrm{TiO}_{2}$ structure was detected at a certain hydrolysis ratio $\left(R_{H} \geq 16\right)$. Even so, relative anatase content was rather insignificant in an aprotic HCl-THF medium, as compared to a differential $\mathrm{HNO}_{3}$-THF medium. Tetragonal $\mathrm{TiO}_{2}$ structure was observed in the entire hydrolysis ratio $\left(4 \leq R_{H} \leq 32\right)$. Interstitial lattice defect was evident in an aprotic $\mathrm{HNO}_{3}$-THF medium but absent in a differential $\mathrm{ClHNO}_{2}$-THF medium.

\section{Introduction}

Titanium dioxide $\left(\mathrm{TiO}_{2}\right)$ nanoparticles are applicable to high performance technologies, as evident in current innovative applications [1]. $\mathrm{TiO}_{2}$ nanoparticles are therefore considered as superior functional materials $[2,3]$. Stoichiometric $\mathrm{TiO}_{2}$ nanoparticles are categorized as active dielectric $(\kappa>3.9)$ materials; nonstoichiometric $\mathrm{TiO}_{2-x}$ nanoparticles are categorized as intrinsic semiconductor materials [4].

$\mathrm{TiO}_{2}$ nanoparticles are proven effective in numerous optoelectronic applications. Such predominant phenomena are related to superior optoelectronic properties: high dielectric constant, high transmission coefficient, and high breakdown strength [5]. $\mathrm{TiO}_{2}$ nanoparticles are also beneficial to several photovoltaic applications [6]. Such predominant phenomena are related to sufficient photoreactive properties [7].

$\mathrm{TiO}_{2}$ nanoparticles are prevalent in three distinct metastable configurations: tetragonal, monoclinic, and orthorhombic [8]. In general, anatase $\mathrm{TiO}_{2}$ nanostructures are more reactive than other polymorphic configurations. Such preferences are attributed to distinctive crystallographic properties [9]. Even so, anatase $\mathrm{TiO}_{2}$ nanostructures are rather difficult to synthesize, as susceptible to phase transformation [10].
In the recent past, anatase $\mathrm{TiO}_{2}$ nanostructures are often derived from sol-gel reaction [11]. Resultant internal nanostructures are more dependent on hydrolysis ratio. Spherical monodisperse nanostructures are achieved at stoichiometric ratio $\left(R_{H}=4\right)$. Resultant internal nanostructures are also dependent on hydrolysis catalyst $[12,13]$. Dense microporous nanostructures are achieved in acidic catalysis $\left(R_{H}>4\right)$; loose mesoporous nanostructures are achieved in basic catalysis.

In the present investigation, $\mathrm{TiO}_{2}$ nanoparticles were achieved in sol-gel synthesis: $\mathrm{HCl}$-THF, $\mathrm{HNO}_{3}$-THF, and $\mathrm{ClHNO}_{2}$-THF catalysis. Resultant $\mathrm{TiO}_{2}$ nanoparticles were then subjected to systematic characterization.

\section{Methods}

2.1. $\mathrm{TiO}_{2}$ Nanoparticles Preparation. $\mathrm{TiO}_{2}$ sol solutions were obtained at a specific $\mathrm{H}_{2} \mathrm{O}$ /alkoxide molar ratio (Table 1). $\mathrm{TiO}_{2}$ sol solutions were stirred at ambient room temperature ( 2 hours). Resultant sol particles were then dried in microwave oven. 
TABLE 1: Hydrolysis molar ratio.

\begin{tabular}{lccc}
\hline $\begin{array}{l}\text { Metal alkoxide } \\
\left(\mathrm{Ti}_{4}\left(\mathrm{OCH}_{2} \mathrm{CH}_{3}\right)_{16}\right)\end{array}$ & Catalysts & Solvent (THF) & $\mathrm{DDH} \mathrm{O}_{2} \mathrm{O}$ \\
\hline 1 & $\left(\mathrm{HCl}, \mathrm{HNO}_{3}\right.$, and $\left.\mathrm{ClHNO}_{2}\right)$ & 4 & 4 \\
1 & 1 & 4 & 8 \\
1 & 1 & 4 & 16 \\
1 & 1 & 4 & 32 \\
\hline
\end{tabular}

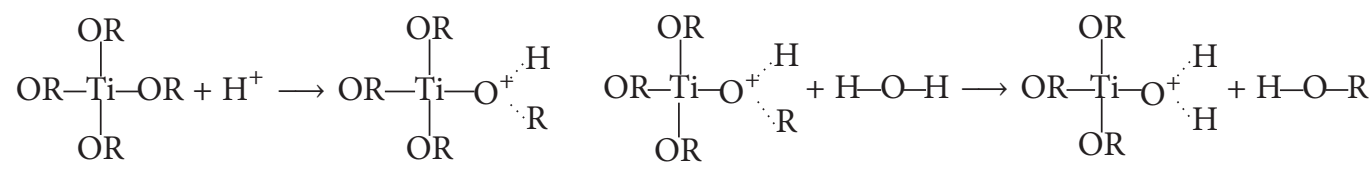

SCHEME 1

2.2. $\mathrm{TiO}_{2}$ Nanoparticles Characterization. DLS analyses were conducted on a Malvern Zetasizer Nano ZS DLS spectrometer (Malvern Instruments $\mathrm{GmbH}$, Herrenberg, Germany). DLS data were acquired in the backscattered mode. DLS data were collected at a fixed detection angle $\left(\theta=173^{\circ}\right)$.

SEM analyses were conducted on a Carl Zeiss LEO 1450 VP microscope (Carl Zeiss AG, Oberkochen, Germany). SEM micrographs were acquired in the backscattered electron (BSE) mode. SEM micrographs were taken at a moderate acceleration voltage $(15-20 \mathrm{kV})$.

XRD analyses were conducted on a Bruker D8 Advance diffractometer (Bruker AXS GmbH, Karlsruhe, Germany). XRD patterns were acquired in the symmetrical BraggBrentano configuration. XRD patterns were recorded in the 2 -theta $(\theta)$ range $\left(15-60^{\circ}\right.$; step size $\left.0.02^{\circ}\right)$.

FTIR analyses were conducted on a Perkin-Elmer Spectrum 400 spectrometer (Perkin-Elmer Ltd, Buckinghamshire, UK). FTIR spectra were acquired in the attenuated total reflectance (ATR) mode. FTIR spectra were recorded in the mid-infrared range $\left(4000-650 \mathrm{~cm}^{-1}\right.$; spectral resolution $\left.4 \mathrm{~cm}^{-1}\right)$.

\section{Results and Discussion}

3.1. Particle Size Distribution and Morphological Characterization. Particle size data was presented in graphical form (histogram), as shown in Figure 1.

Broad particle size distribution was observed at high hydrolysis ratio $\left(R_{H}=32\right)$. Broad particle size distribution is attributed to rapid condensation reaction, as commenced before hydrolysis completion.

Particle growth process is accelerated at high condensation rate [14]. In such a case, particle growth process is pertained to monomers (Ti-OH) addition. Particle growth rate is dependent on interface reaction. In effect, rapid growth rate is expected at high monomers concentration. Dense aggregate structure $\left(D_{f} \approx 3.00\right)$ is predominant in monomers addition.

Narrow particle size distribution was observed at moderate hydrolysis ratio $\left(8 \leq R_{H} \leq 16\right)$. Narrow particle size distribution is attributed to more efficient hydrolysis reaction [15].
Distinct growth process is anticipated at high hydrolysis rate (Figure 2). More specific, particle growth process is pertained to clusters (Ti-OH-Ti) aggregation [16]. Particle growth rate is dependent on Brownian motion. In effect, rapid growth rate is expected at high effective collision. Fractal aggregate structure $\left(D_{f} \approx 2.09\right)$ is predominant in clusters aggregation.

Broad particle size distribution was observed in $\mathrm{HCl}-\mathrm{THF}$ medium. Broad particle size distribution is attributed to concurrent hydrolysis and condensation reactions. Such critical phenomenon is correlated to insignificant acidification.

Narrow particle size distribution was observed in $\mathrm{HNO}_{3}$ THF medium. Narrow particle size distribution is attributed to sequential hydrolysis and condensation reactions. Such critical phenomenon is correlated to significant protonation.

Particle formation process is preferred in high acidic medium. In particular, $S_{N} 1$ mechanism is involved in high acidic medium. Local equilibrium behavior is dependent on ionic strength gradient.

Metal alkoxide (Ti-OR) group is protonated in the initial step. In such a case, $\mathrm{Ti}-\mathrm{OR}^{+\bullet}$ species is susceptible to hydrolysis reaction (Scheme 1).

Reactive $\mathrm{Ti}-\mathrm{OH}^{+}$species can react further in the subsequent step. Ti-O-Ti network structure is achieved in oxolation reaction; $\mathrm{M}-\mathrm{OH}-\mathrm{M}$ network structure is achieved in olation reaction (Scheme 2).

Smallest particle size data $\left(R_{H}=16\right)$ is subjected to SEM measurement. DLS particle size data is based on hydrodynamic parameter, and therefore, resultant particle size distribution is much broader than SEM result. Similar observation was also reported in several previous studies [17].

Small aggregate particles were discerned in uniform bright contrast. Each aggregate particle does not exceed $50 \mathrm{~nm}$ in size. Small aggregate particles are attributed to attractive interparticle interactions, electrostatic attractive force, and covalent interactive force.

3.2. Phase Identification. Diffraction pattern was presented in the 2-theta range $\left(15^{\circ}<2 \theta<65^{\circ}\right)$, as shown in Figure 3 .

Broad diffraction hump was obtained at low hydrolysis ratio $\left(R_{H} \leq 8\right)$. Broad diffraction hump was observed 


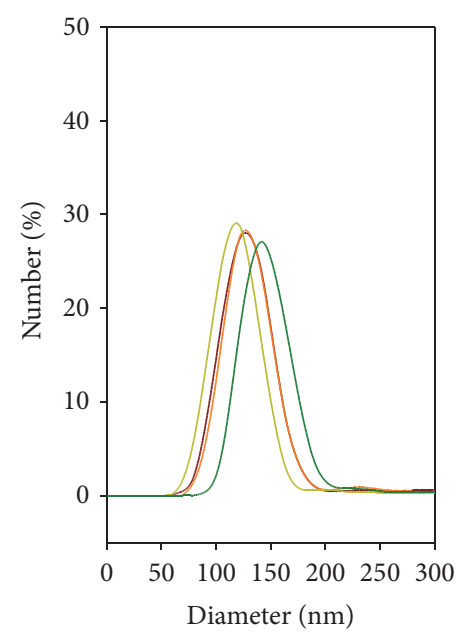

$R_{H}=4 \longrightarrow R_{H}=16$
$-R_{H}=8-R_{H}=32$

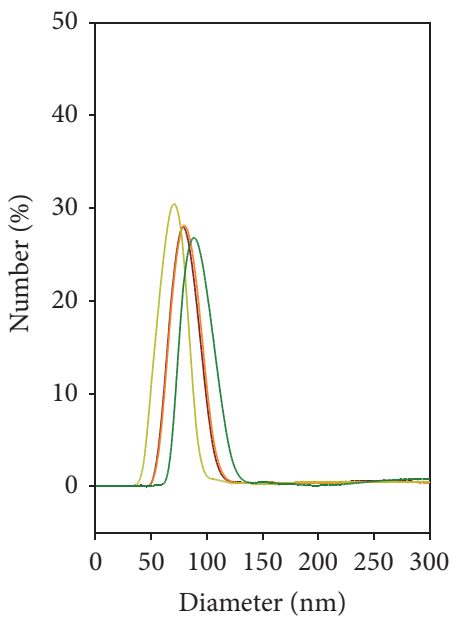

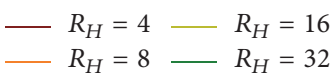

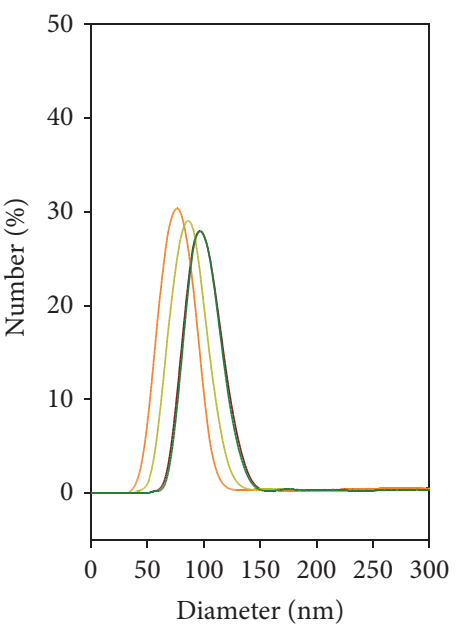

$\begin{aligned} R_{H}=4 & -R_{H}=16 \\ -R_{H}=8 & -R_{H}=32\end{aligned}$

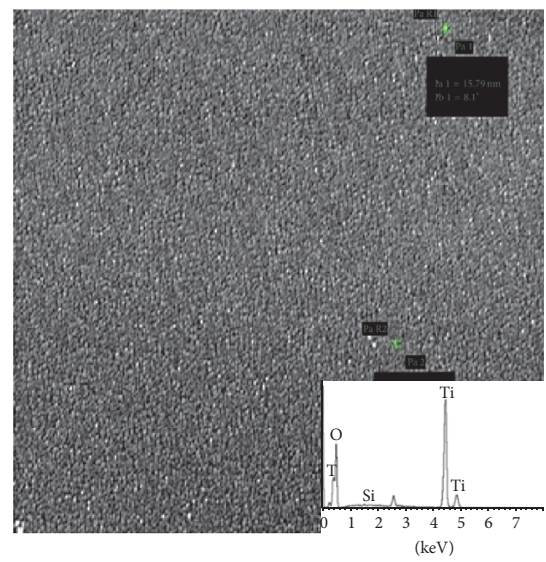

(a)

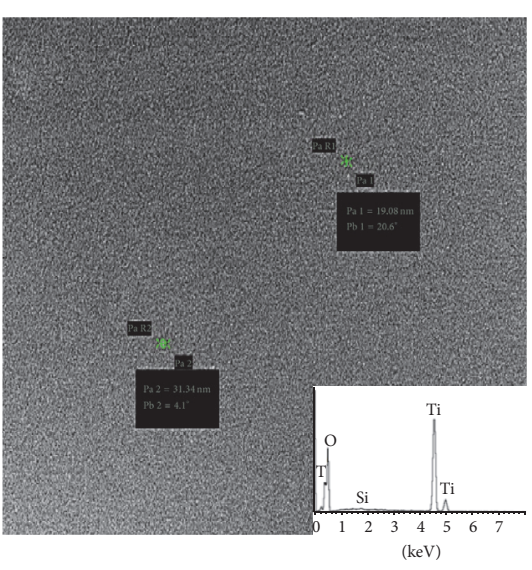

(b)

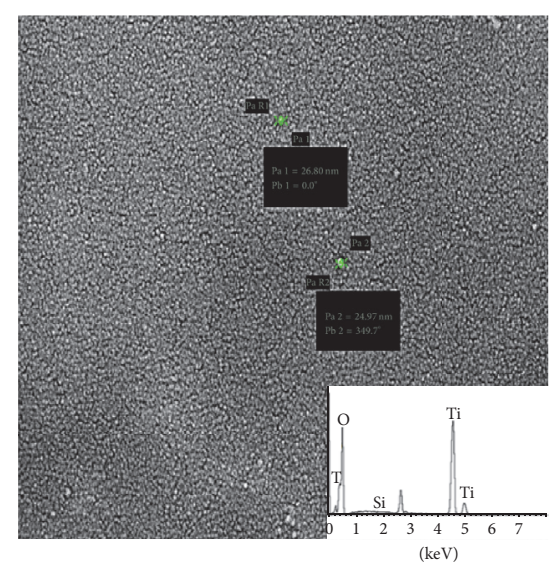

(c)

Figure 1: Particle size data and SEM micrograph: (a) $\mathrm{HCl}-\mathrm{THF} / \mathrm{TiO}_{2}$, (b) $\mathrm{HNO}_{3}-\mathrm{THF} / \mathrm{TiO}_{2}$, and (c) $\mathrm{ClHNO}_{2}-\mathrm{THF} / \mathrm{TiO}$ nanoparticles. 


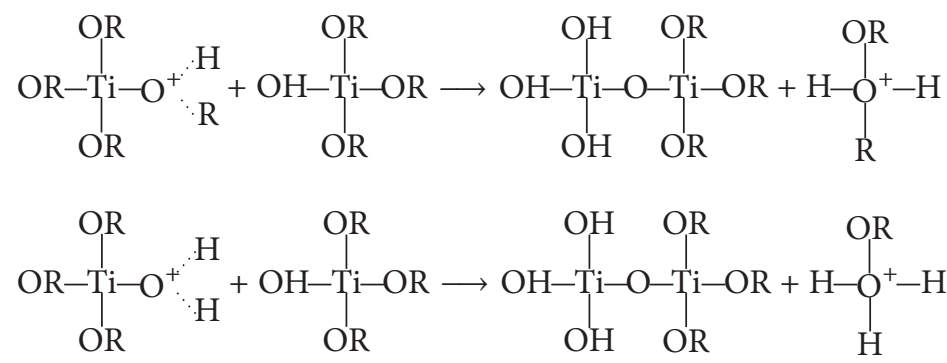

SCHeme 2

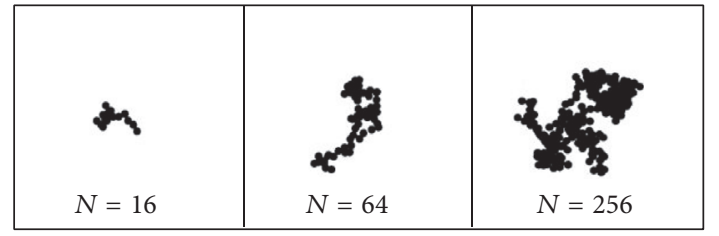

(a)

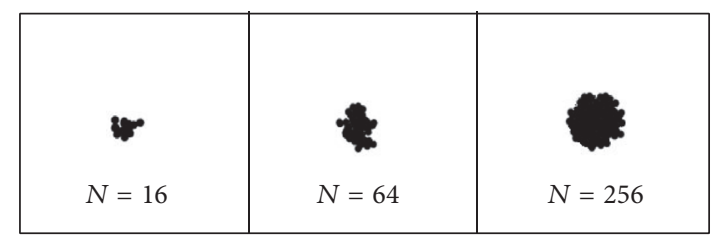

(b)

FIgURE 2: Particle growth mechanism: (a) clusters aggregation and (b) monomers addition.

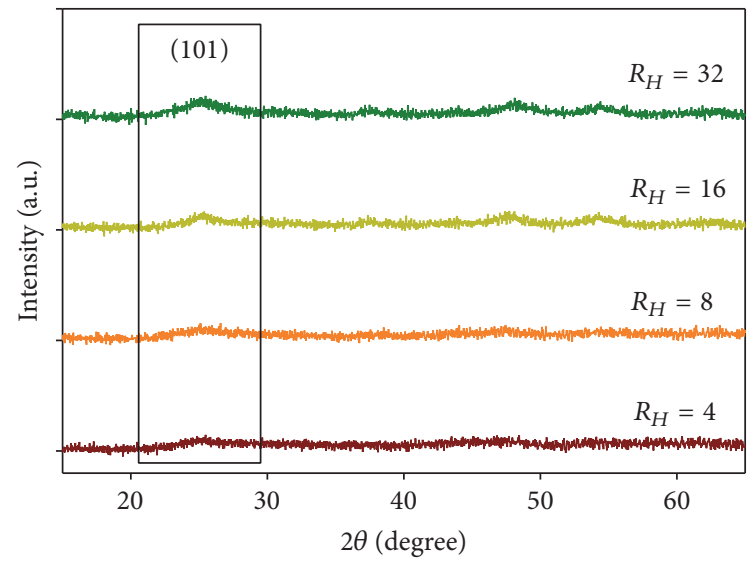

(a)

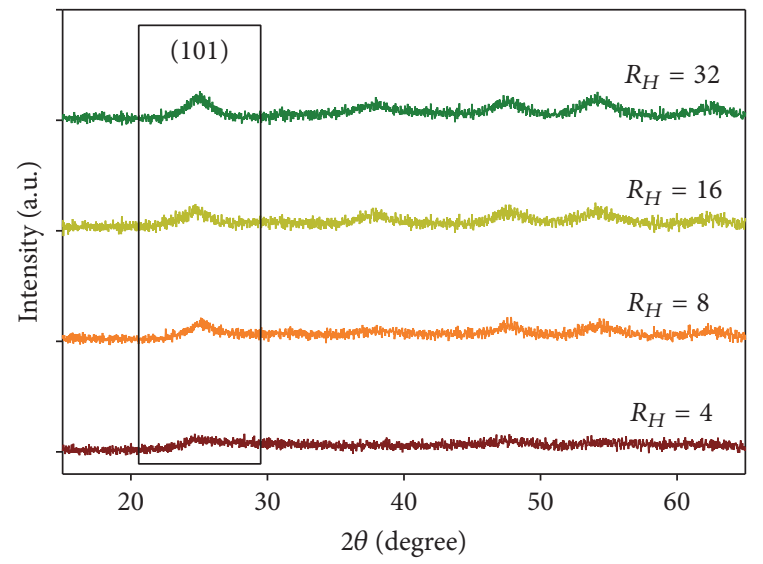

(b)

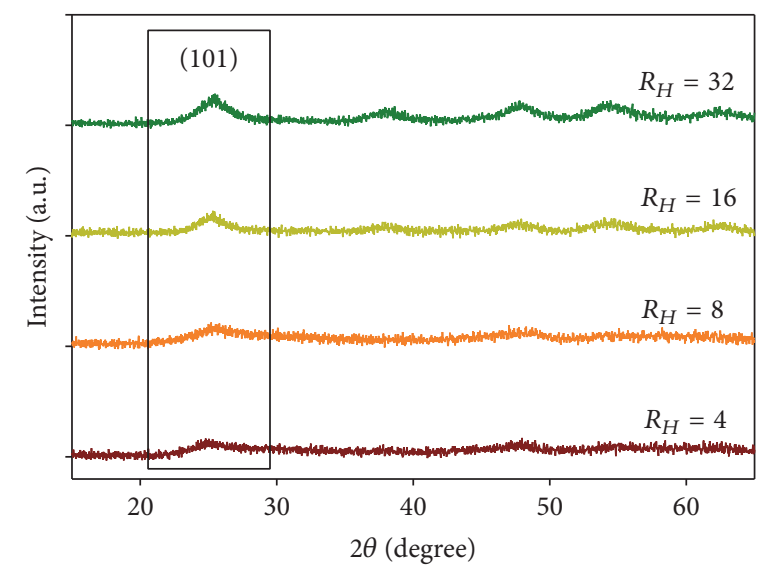

(c)

FIGURE 3: XRD diffraction patterns: (a) $\mathrm{HCl}-\mathrm{THF} / \mathrm{TiO}_{2}$, (b) $\mathrm{HNO}_{3}-\mathrm{THF} / \mathrm{TiO}_{2}$, and (c) $\mathrm{ClHNO}_{2}-\mathrm{THF} / \mathrm{TiO}_{2}$ nanoparticles. 


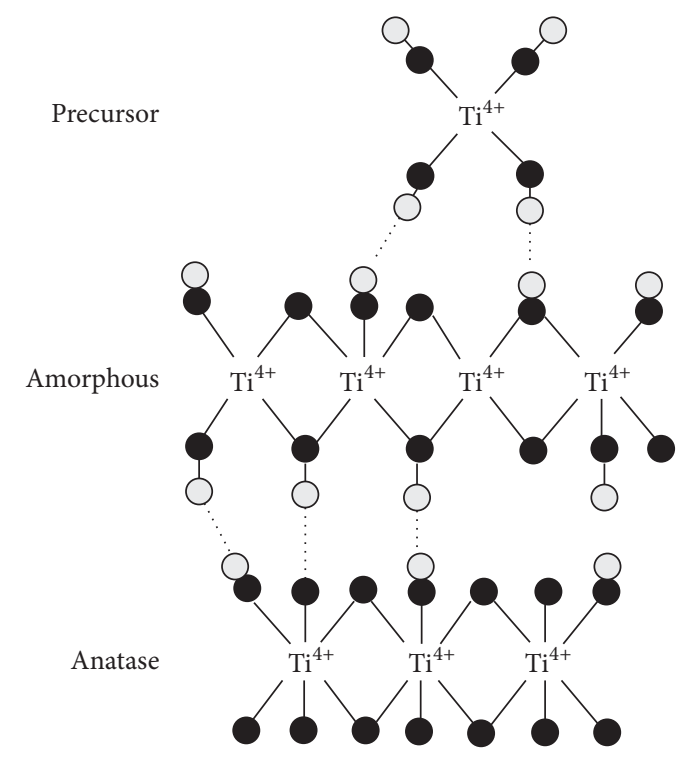

FIgURE 4: Titanium-oxygen (Ti-O) lattice rearrangement.

at $2 \theta=25.3^{\circ}$. Such diffraction hump is attributed to random lattice orientation. In this particular case, amorphous $\mathrm{TiO}_{2}$ nanostructure is encountered in sixfold octahedral coordination but no fourfold tetrahedral coordination.

Broad intense diffraction band was observed at high hydrolysis ratio $\left(R_{H} \geq 16\right)$. Preferable anatase diffraction band was detected at $2 \theta=25.3^{\circ}(101), 37.9^{\circ}$ (004), 48.1 (200), $54.3^{\circ}$ (105), and $62.5^{\circ}$ (204).

More specific, anatase $\mathrm{TiO}_{2}$ nanostructure is achieved in gradual titanium-oxygen lattice rearrangement, that is, $\mathrm{Ti}$ $\mathrm{O}$ bonds disproportionation (Figure 4). In literature, anatase $\mathrm{TiO}_{2}$ nanostructure is arranged in fourfold coordination: each $\mathrm{Ti}$ atom is linked to six oxygen atoms; each oxygen atom is linked to three Ti atoms [18].

Less intense diffraction band was obtained in $\mathrm{HCl}-\mathrm{THF}$ medium. In such a case, phase transformation process is restricted in $\mathrm{HCl}-\mathrm{THF}$ catalysis.

Broad intense diffraction band was obtained in $\mathrm{HNO}_{3}$ THF medium. In such a case, phase transformation process is preferred in $\mathrm{HNO}_{3}$-THF catalysis. Phase transformation process is mediated at low ambient supersaturation. Such critical phenomenon is attributed to rapid hydrolysis reaction.

Phase transformation process is spontaneous in aqueous acidic medium. Phase transformation process can occur in multiple distinct stages: nucleation, growth, and further coalescence [19]. Nucleation process is achieved in successive monomers condensation. Nucleation process is preferred above critical crystallite size, that is, 12 Ti-O bonds dimension. In general, nucleation rate is dependent on monomers concentration.

Crystallite growth process is achieved in monomers ( $\mathrm{Ti}-$ $\mathrm{OH}$ ) addition. Crystallite growth process is based on interface reaction, as involved in mass transfer (or heat transfer). In effect, crystallite growth rate is dependent on thermodynamic properties.
3.3. Structural Characterization. IR absorption spectrum was presented in the mid-infrared region $\left(4000-650 \mathrm{~cm}^{-1}\right)$, as shown in Figure 5.

$\mathrm{TiO}_{2}$ characteristic band was obtained in HCl-THF and $\mathrm{ClHNO}_{2}$-THF medium. Ti-O absorption band was observed at 950 and $850 \mathrm{~cm}^{-1}$. Such absorption band is assigned to tetrahedral $\left[\mathrm{TiO}_{4}\right]^{4-}$ units. In such a case, Ti-O network structure is encountered in tetrahedral $\left[\mathrm{TiO}_{4}\right]^{4-}$ coordination.

Ti-OH absorption band was observed at $3800-3750 \mathrm{~cm}^{-1}$, but not obvious. In such a case, subsequent condensation reaction is continued till tetrahedral $\left[\mathrm{TiO}_{4}\right]^{4-}$ formation.

Board hydroxyl absorption band was observed at $3600-3000 \mathrm{~cm}^{-1}$. Broad absorption band is attributed to intermolecular interactions (e.g., $\mathrm{H}_{2} \mathrm{O} \cdots \mathrm{H}_{2} \mathrm{O}$ and/or $\mathrm{Ti}-\mathrm{OH} \cdots \mathrm{H}_{2} \mathrm{O}$ interactions) (Figure 6). In general, surface hydroxyl group is resided at octahedral surface. Surface hydroxyl group is beneficial in photocatalytic activities.

Surface $\mathrm{H}_{2} \mathrm{O}$ absorption band was observed at $1620 \mathrm{~cm}^{-1}$. Surface $\mathrm{H}_{2} \mathrm{O}$ absorption process is beneficial to heat generation, as consequence in $\mathrm{Ti}^{4+}-\mathrm{OH}_{2}$ bonds formation. In effect, phase transformation process is possible in ambient operational condition.

$\mathrm{N}-\mathrm{TiO}_{2}$ characteristic band was obtained in observed in $\mathrm{HNO}_{3}$-THF medium. Ti-O-N absorption band was observed at 1550,1300 , and $1050 \mathrm{~cm}^{-1}$. Such absorption band is corresponded to interstitial nitrogen sites. In such a case, Ti-O-N network structure is encountered in interstitial coordination, rather than substitutional coordination (Figure 7).

Nitrate $\left(\mathrm{NO}_{3}\right)$ absorption band was observed at $1400 \mathrm{~cm}^{-1}$. Nitrate anion is chelated in bidentate fashion, and therefore, nitrate anion is rather difficult to eliminate.

\section{Conclusions}

Resultant $\mathrm{TiO}_{2}$ nanostructure was dependent on chemical reaction parameters. Narrower size range was obtained at a 


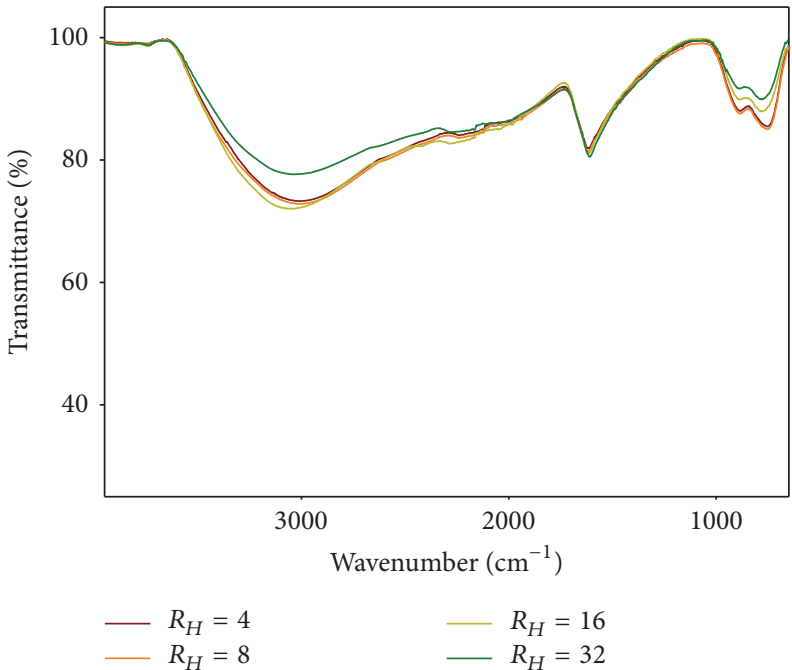

(a)

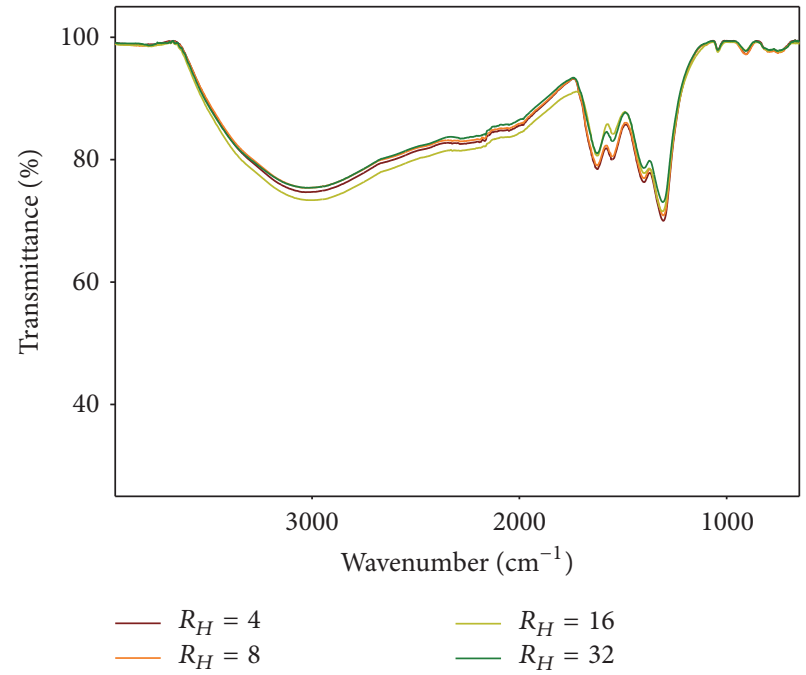

(b)

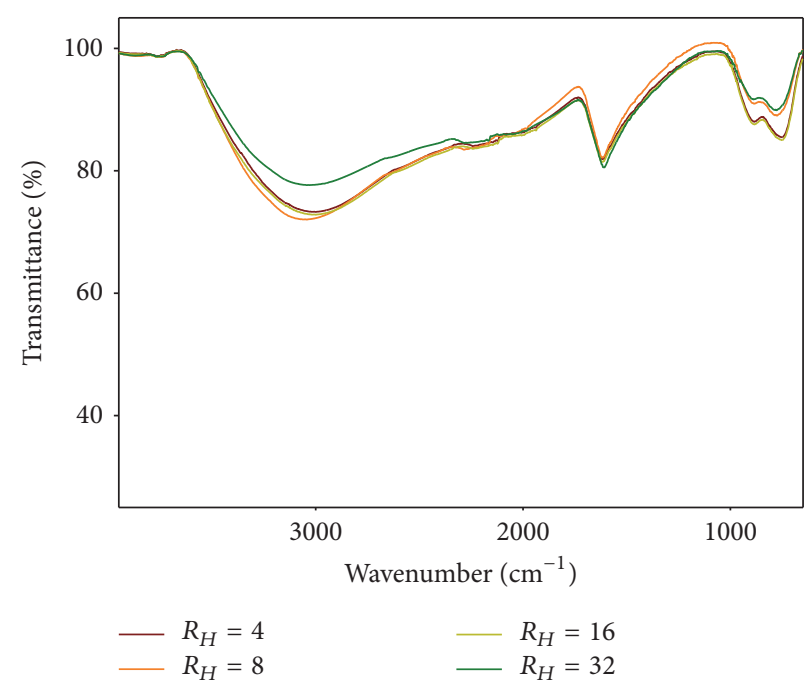

(c)

FIGURE 5: IR absorption spectra: (a) $\mathrm{HCl}-\mathrm{THF} / \mathrm{TiO}_{2}$, (b) $\mathrm{HNO}_{3}-\mathrm{THF} / \mathrm{TiO}_{2}$, and (c) $\mathrm{ClHNO}_{2}-\mathrm{THF} / \mathrm{TiO}_{2}$ nanoparticles.

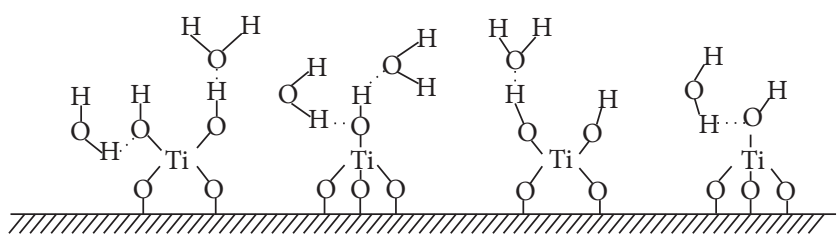

(a)

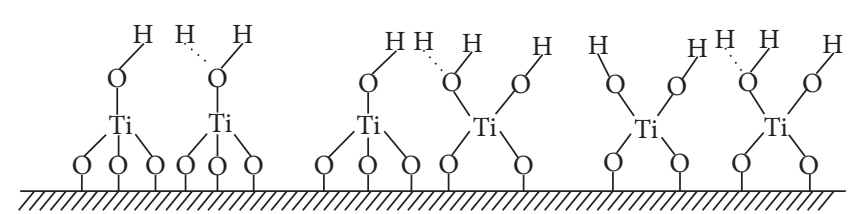

(b)

FIGURE 6: H-bonds formation mechanism: (a) Ti-OH $\cdots \mathrm{H}_{2} \mathrm{O}$ interaction and (b) Ti-OH $\cdots \mathrm{HO}-\mathrm{Ti}$ interaction.

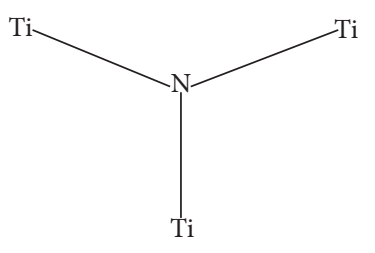

Substitutional position

(a)

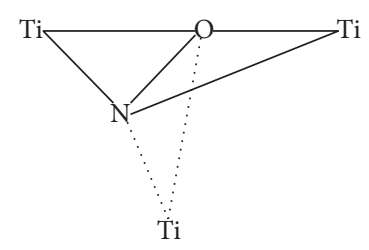

Interstitial position

(b)

FIGURE 7: Ti-O-N network formation: (a) substitutional coordination and (b) interstitial coordination. 
moderate hydrolysis ratio $\left(R_{H}=16\right)$. Substantial anatase phase was achieved in a certain hydrolysis ratio $\left(R_{H} \geq 16\right)$. Even more, interstitial lattice defect was developed in an aprotic $\mathrm{HNO}_{3}$-THF medium.

\section{Competing Interests}

The authors declare that they have no competing interests.

\section{Acknowledgments}

O. L. Kang would like to extend his sincere appreciation to Universiti Kebangsaan Malaysia for financial support through University Research Grants (1) NND/NM(2)/TD11046, (2) ERGS/1/2013/TK07/UKM/02/4, and (3) FRGS/1/ 2014/ST01/UKM/02/1. O. L. Kang would also like to extend his sincere appreciation to the CRIM for technical support. U. A. Rana would like to extend his sincere appreciation to King Saud University for financial support through Prolific Research Group, Project no. PRG-1436-18.

\section{References}

[1] M. Sharon, F. Modi, and M. Sharon, "Titania based nanocomposites as a photocatalyst: a review," AIMS Materials Science, vol. 3, no. 3, pp. 1236-1254, 2016.

[2] J. Mech, K. Mech, and K. Szaciłowski, " $\mathrm{TiO}_{2}$-anthraquinone hybrids: from quantum-chemical design to functional materials," Journal of Materials Chemistry C, vol. 3, no. 16, pp. 41484155, 2015.

[3] O. L. Kang, A. Ahmad, N. H. Hassan, and U. A. Rana, "[MG49$\left.\mathrm{LiClO}_{4}\right]$ : $\left[\mathrm{TiO}_{2}-\mathrm{SiO}_{2}\right]$ polymer electrolytes: in situ preparation and characterization," International Journal of Polymer Science, vol. 2016, Article ID 9838067, 10 pages, 2016.

[4] A. Di Paola, M. Bellardita, and L. Palmisano, "Brookite, the least known $\mathrm{TiO}_{2}$ photocatalyst," Catalysts, vol. 3, no. 1, pp. 36-73, 2013.

[5] T. A. Kandiel, A. Feldhoff, L. Robben, R. Dillert, and D. W. Bahnemann, "Tailored titanium dioxide nanomaterials: anatase nanoparticles and brookite nanorods as highly active photocatalysts," Chemistry of Materials, vol. 22, no. 6, pp. 2050-2060, 2010.

[6] B. Laskova, M. Zukalova, A. Zukal, M. Bousa, and L. Kavan, "Capacitive contribution to Li-storage in $\mathrm{TiO}_{2}$ (B) and $\mathrm{TiO}_{2}$ (anatase)," Journal of Power Sources, vol. 246, pp. 103-109, 2014.

[7] F. Fresno, R. Portela, S. Suárez, and J. M. Coronado, "Photocatalytic materials: recent achievements and near future trends," Journal of Materials Chemistry A, vol. 2, no. 9, pp. 2863-2884, 2014.

[8] K. Sabyrov, N. D. Burrows, and R. L. Penn, "Size-dependent anatase to rutile phase transformation and particle growth," Chemistry of Materials, vol. 25, no. 8, pp. 1408-1415, 2013.

[9] F. De Angelis, C. Di Valentin, S. Fantacci, A. Vittadini, and A. Selloni, "Theoretical studies on anatase and less common $\mathrm{TiO}_{2}$ phases: bulk, surfaces, and nanomaterials," Chemical Reviews, vol. 114, no. 19, pp. 9708-9753, 2014.

[10] A. Fujishima, X. Zhang, and D. A. Tryk, " $\mathrm{TiO}_{2}$ photocatalysis and related surface phenomena," Surface Science Reports, vol. 63, no. 12, pp. 515-582, 2008.
[11] E. Blanco, J. M. González-Leal, and M. Ramírez-del Solar, "Photocatalytic $\mathrm{TiO}_{2}$ sol-gel thin films: optical and morphological characterization," Solar Energy, vol. 122, pp. 11-23, 2015.

[12] R. Ciriminna, A. Fidalgo, V. Pandarus, F. Béland, L. M. Ilharco, and M. Pagliaro, "The sol-gel route to advanced silica-based materials and recent applications," Chemical Reviews, vol. 113, no. 8, pp. 6592-6620, 2013.

[13] J. A. Van Hensbergen, M. Liu, R. P. Burford, and A. B. Lowe, "Simultaneous ROMP and titania sol-gel reactions and nanodispersed functional organic-inorganic composite hybrid materials," Journal of Materials Chemistry C, vol. 3, no. 3, pp. 693-702, 2015.

[14] M. K. Patil, S. Shaikh, and G. Ibram, "Recent advances on $\mathrm{TiO}_{2}$ thin film based photocatalytic applications (a review)," Current Nanoscience, vol. 11, no. 3, pp. 271-285, 2015.

[15] S. Laurent, D. Forge, M. Port et al., "Magnetic iron oxide nanoparticles: synthesis, stabilization, vectorization, physicochemical characterizations and biological applications," Chemical Reviews, vol. 108, no. 6, pp. 2064-2110, 2008.

[16] S. Babu, M. Rottereau, T. Nicolai, J. C. Gimel, and D. Durand, "Flocculation and percolation in reversible clustercluster aggregation," European Physical Journal E, vol. 19, no. 2, pp. 203-211, 2006.

[17] R. Raliya, P. Biswas, and J. C. Tarafdar, " $\mathrm{TiO}_{2}$ nanoparticle biosynthesis and its physiological effect on mung bean (Vigna radiata L.)," Biotechnology Reports, vol. 5, no. 1, pp. 22-26, 2015.

[18] P. Giesz, G. Celichowski, D. Puchowicz et al., "Microwaveassisted $\mathrm{TiO}_{2}$ : anatase formation on cotton and viscose fabric surfaces," Cellulose, vol. 23, no. 3, pp. 2143-2159, 2016.

[19] B. Gilbert, H. Zhang, F. Huang, M. P. Finnegan, G. A. Waychunas, and J. F. Banfield, "Special phase transformation and crystal growth pathways observed in nanoparticles," Geochemical Transactions, vol. 4, pp. 20-27, 2003. 

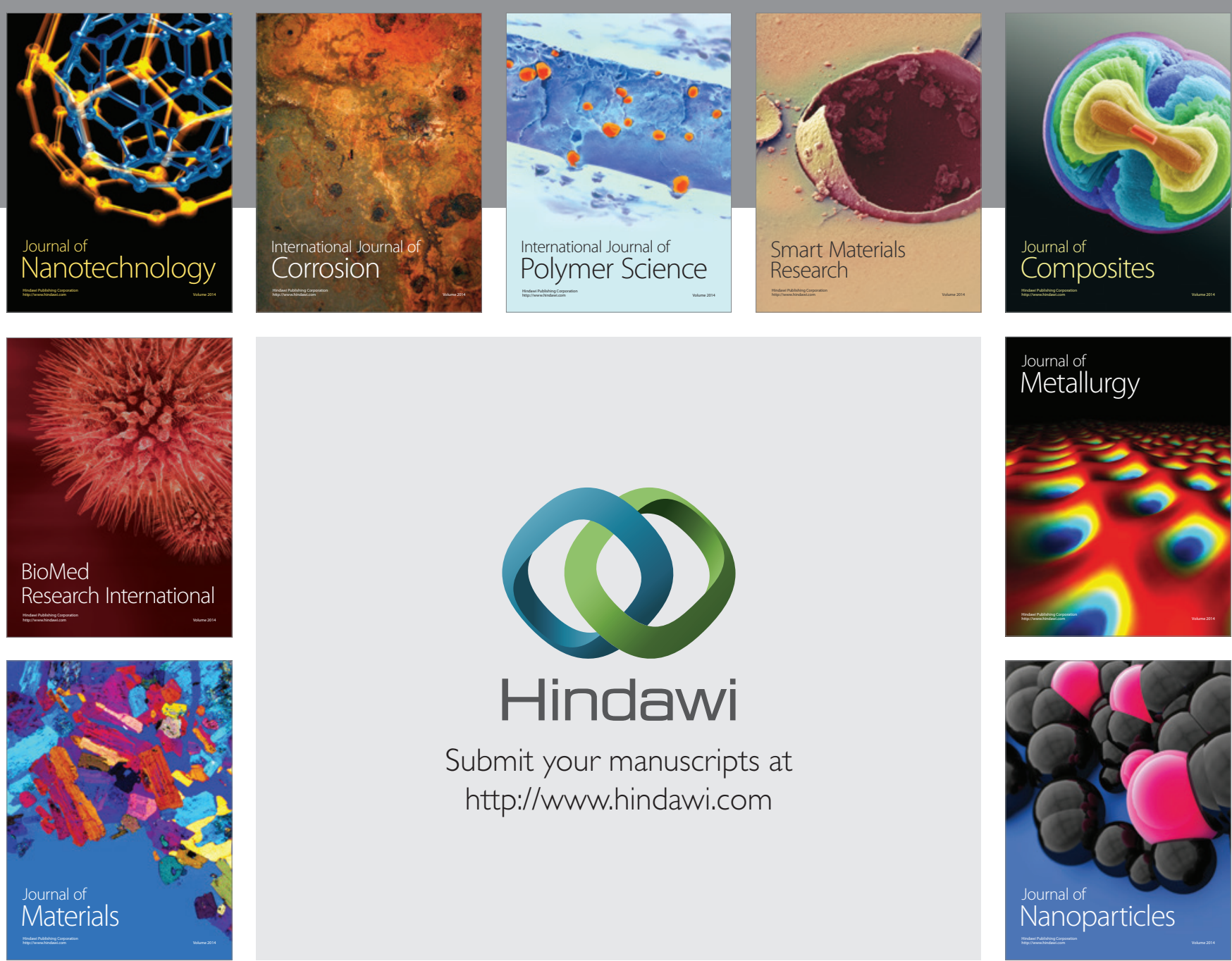

\section{Hindawi}

Submit your manuscripts at

http://www.hindawi.com

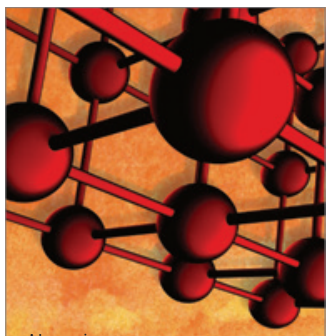

Materials Science and Engineering
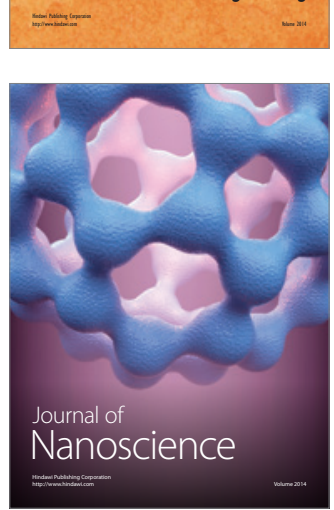
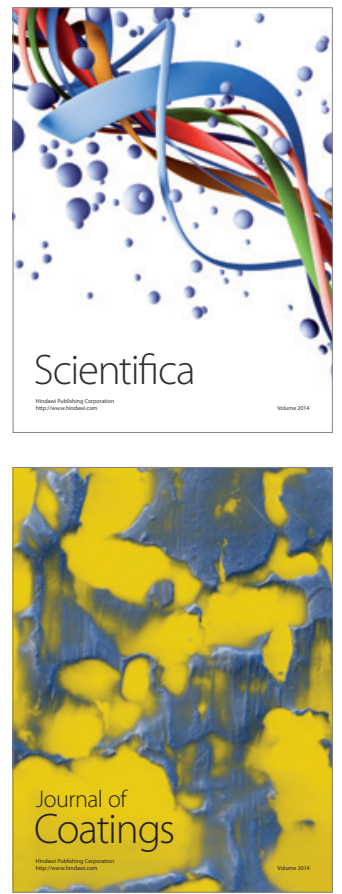
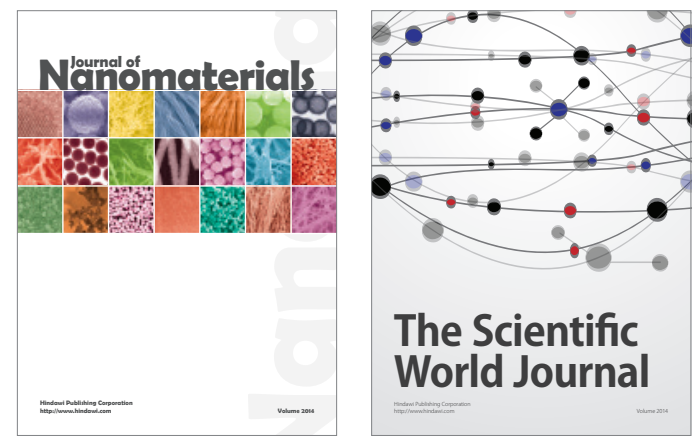

The Scientific World Journal
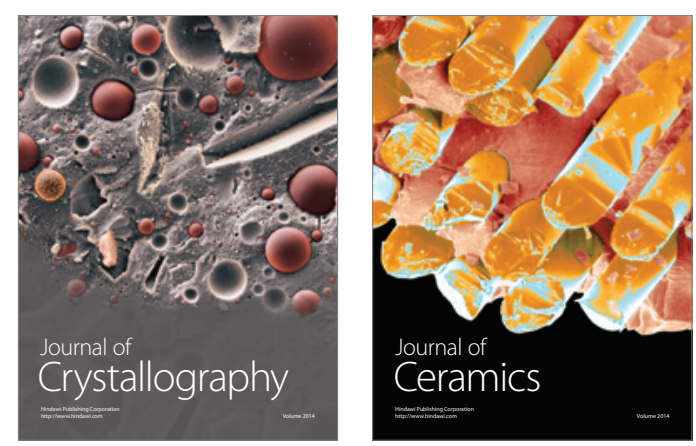
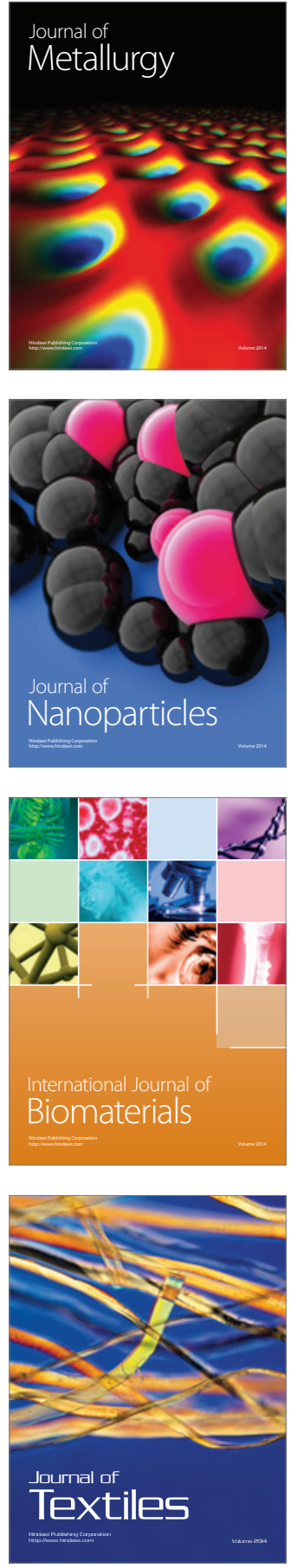